\title{
Interactive Energy Atlas for Colorado and New Mexico: An Online Resource for Decisionmakers
}

Throughout the western United States, increased demand for energy is driving the rapid development of oil, gas (including shale gas and coal-bed methane), and uranium, as well as renewable energy resources such as geothermal, solar, and wind. Much of the development in the West is occurring on public lands, including those under Federal and State jurisdictions. In Colorado and New Mexico, these public lands make up about 40 percent of the land area. Both States benefit from the revenue generated by energy production, but resource managers and other decisionmakers must balance the benefits of energy development with the potential consequences for ecosystems, recreation, and other resources. Although a substantial amount of geospatial data on existing energy development and energy potential is available, much of this information is not readily accessible to natural resource decisionmakers, policymakers, or the public. Furthermore, the data often exist in varied formats, requiring considerable processing before these datasets can be used to evaluate tradeoffs among resources, compare development alternatives, or quantify cumulative effects.

To allow for a comprehensive evaluation among different energy types, an interdisciplinary team of U.S. Geological Survey (USGS) scientists has developed an online Interactive Energy Atlas (Energy Atlas) (http://my.usgs.gov/eerma/) for Colorado and New Mexico. The purpose of the Energy Atlas is to facilitate access to geospatial data related to energy resources, energy infrastructure, and natural resources that may be affected by energy development. The Energy Atlas is designed to meet the needs of varied users, including geographic information system (GIS) analysts, resource managers, policymakers, and the public, who seek information about energy in the western United States. Currently (2013), the Energy Atlas has two primary capabilities: a GIS data viewer and an interactive map gallery.

\section{GIS Data Viewer}

The GIS data viewer allows users to preview and download GIS data related to energy potential and development for oil and gas, coal, uranium, solar, wind, and geothermal resources in Colorado and New Mexico. Along with GIS data from different sources, the Energy Atlas features new USGS geospatial datasets for wind and solar energy facilities in both States. Other energy-related GIS layers include data obtained from USGS data series and energy assessments, the Colorado Oil and Gas Commission, the U.S. National Atlas, and the National Renewable Energy Laboratory. Data related to natural resources also are provided and include layers for hydrology, land cover, and land-protection status. All GIS layers and associated metadata can be previewed online prior to downloading. The GIS data viewer and geospatial data that are available on the Energy Atlas represent a valuable resource for experienced GIS users.

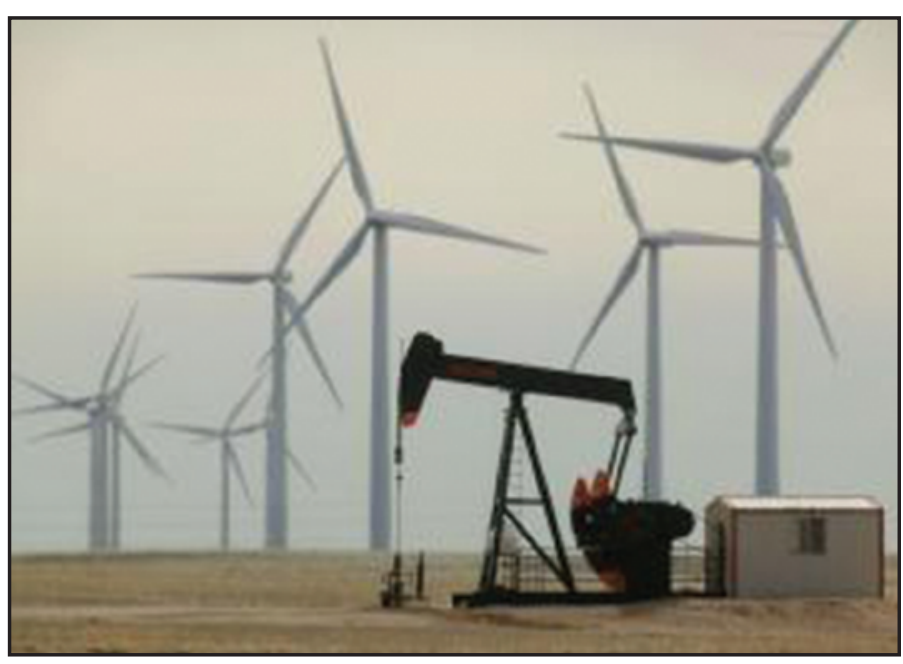

Oil pump jack and windfarm near Peetz, Colorado. (Photograph by Tasha Carr, USGS, 2013)

\section{Locations and Attributes of Wind Turbines in Colorado, 2011}

View Full FGDC Metadata

Download Dataset Now

Abstract: This dataset represents an update to U.S. Geological Survey Data Series 597. Locations and attributes of wind turbines in Colorado, 2009 (available at http://pubs.usgs.gov/ds/597/). This updated Colo... (More)

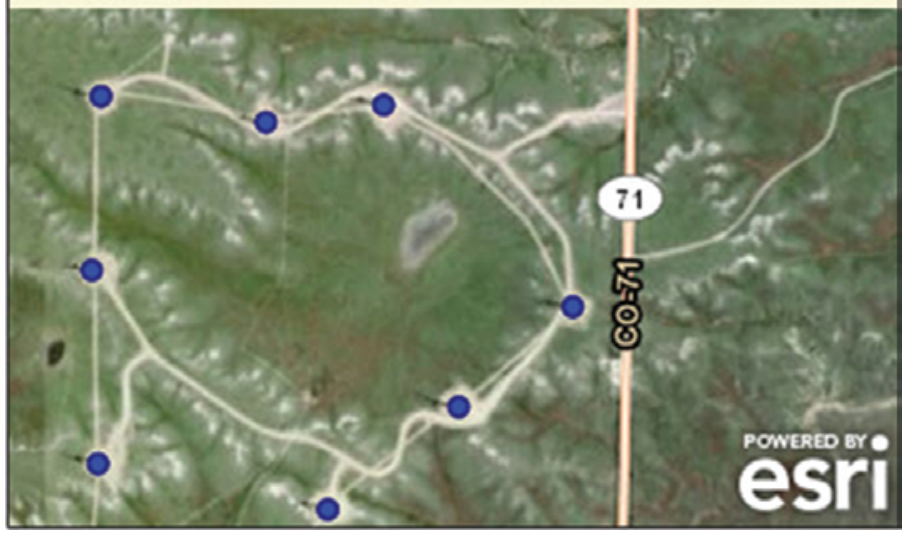

Screenshot of the GIS viewer, which allows users to view and interact with geospatial data before downloading. 


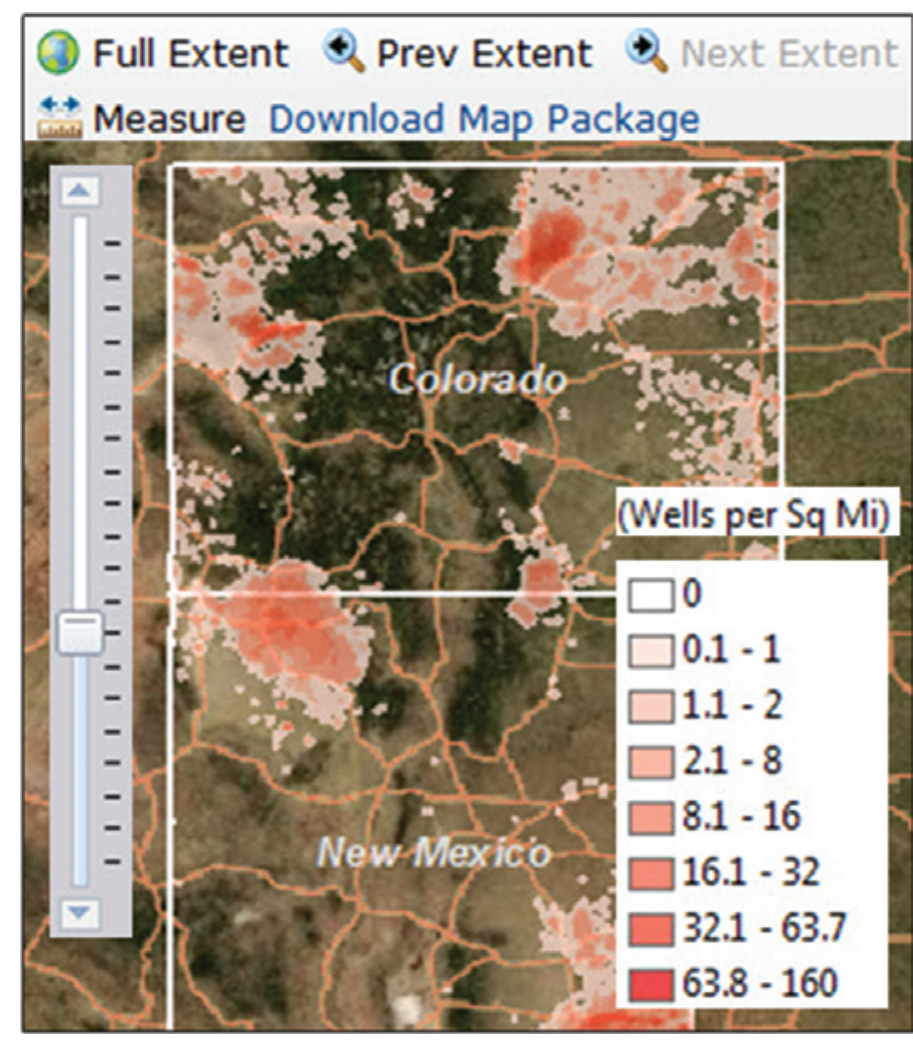

Screenshot of an interactive map showing thematically organized energy datasets for visualization and further analysis. Several different interactive maps are available, including a map of all energy types combined and maps of energy development by type (for example, wind, solar, oil and gas).

\section{Interactive Map Gallery}

The interactive map gallery contains a collection of maps that compile and summarize thematically related data layers in a user-friendly format. The maps are dynamic, allowing users to explore data at different resolutions and obtain information about the features being displayed. For example, an oil and gas map is provided, which depicts active wells in Colorado and New Mexico. At the largest extent, a user can view well-density categories, or alternatively, well-pad densities (these values are different if multiple wells are drilled on one pad). As the user zooms in, detailed well-pad locations appear, as well as information about directional drill lines connecting wells and well pads (where those data are available). Additional information, such as well type or production quantity, can be displayed by selecting an individual well on the map. The interactive maps allow users to pan, zoom in and out, turn data layers on and off, identify features, and change the underlying base map. Satellite imagery constitutes one base map, which allows the user to see the actual disturbance footprint associated with the development of the different energy resources. All interactive maps can be downloaded directly from the Energy Atlas and are designed for less experienced GIS users who want to view multiple data layers simultaneously. Samples of the interactive maps are highlighted in several slide shows on the Energy Atlas Web site.

The Energy Atlas also includes an interactive decisionsupport tool, which allows users to visualize the relative amount of the landscape potentially affected by human disturbance associated with energy development. Users can explore how landscapes might differ for species that vary in their sensitivity to disturbance. For land managers concerned with a particular species or other specific objectives, this type of application can be useful for considering the current state of the landscape, and it can be used to compare alternate development scenarios.

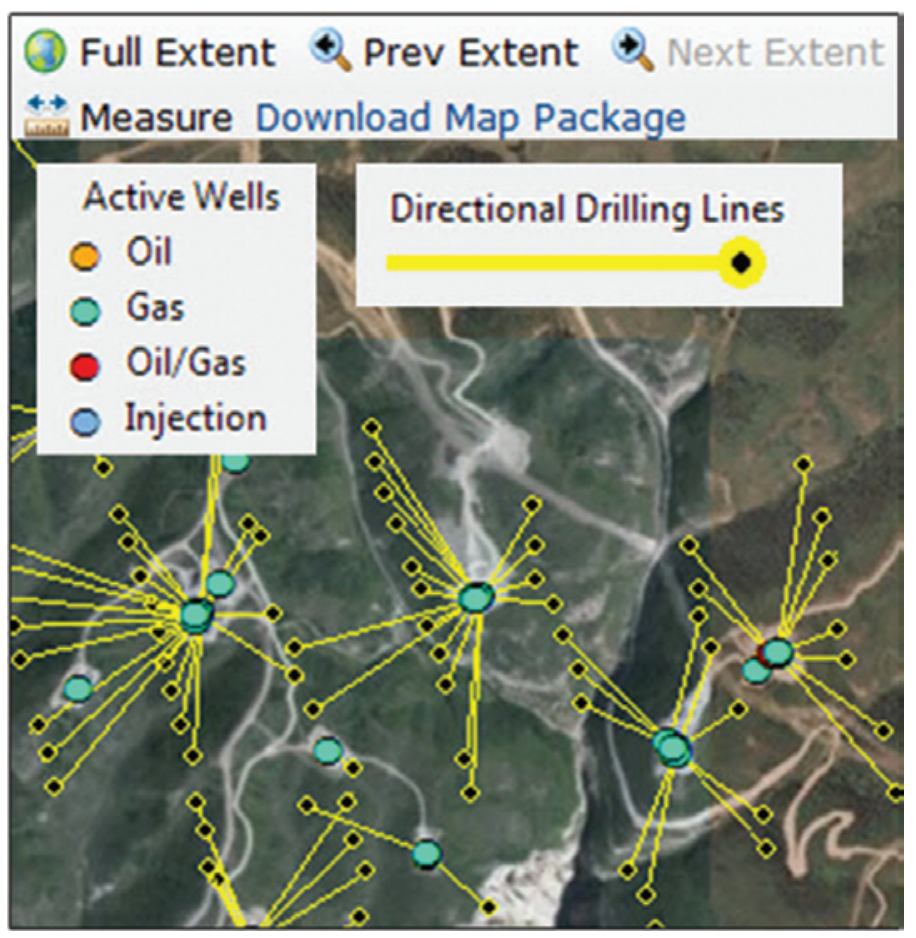

Screenshot of interactive map showing dynamic data layers, which provide more detail as the user zooms in for a close-up view. This allows relevant details to be dynamically displayed at appropriate spatial extents.

Energy Atlas Web site: http:/my.usgs.gov/eerma/

\begin{tabular}{|ll|}
\hline \multicolumn{2}{|c|}{ Contact Information } \\
Tasha Carr & Natalie Latysh \\
970.226 .9446 & 303.202 .4637 \\
carrn@usgs.gov & nlatysh@usgs.gov \\
Jay Diffendorfer & Anne Marie Matherne \\
303.236.2885 & 505.830 .7971 \\
jediffendorfer@usgs.gov & matherne@usgs.gov \\
Ken Leib & Sarah Hawkins \\
970.245 .5257 & 970.245 .5257 \\
kjleib@usgs.gov & shawkins@usgs.gov \\
Josh Linard & Drew Ignizio \\
970.245.5257 & 970.226 .9213 \\
jilinard@usgs.gov & dignizio@usgs.gov \\
\hline
\end{tabular}

